\title{
A New Animal Model for Studying Lyme Disease Spirochetes in a Mammalian Host-adapted State
}

\author{
Darrin R. Akins, ${ }^{\star}$ Kenneth W. Bourell, ${ }^{*}$ Melissa J. Caimano, ${ }^{\star}$ Michael V. Norgard, ${ }^{\ddagger}$ and Justin D. Radolf ${ }^{\star \ddagger}$ \\ $*$ Department of Internal Medicine and ${ }^{\ddagger}$ Department of Microbiology, University of Texas Southwestern Medical Center, Dallas, \\ Texas 75235
}

\begin{abstract}
There is now substantial evidence that Borrelia burgdorferi, the Lyme disease spirochete, undergoes major alterations in antigenic composition as it cycles between its arthropod and mammalian hosts. In this report, we cultivated $B$. burgdorferi 297 within dialysis membrane chambers implanted into the peritoneal cavities of rats to induce antigenic changes similar to those which occur during mammalian infection. Chamber-grown spirochetes, which remained fully virulent, did not express either outer surface protein A or Lp6.6, lipoproteins known to be downregulated after mammalian infection. However, they did, express p21, a well characterized outer surface protein $\mathrm{E}$ homologue, which is selectively expressed during infection. SDS-PAGE, two-dimensional gel electrophoresis, and immunoblot analysis revealed that chamber-grown borreliae also expressed uncharacterized proteins not expressed by in vitro-cultivated spirochetes; reactivity with sera from mice chronically infected with B. burgdorferi 297 confirmed that many of these novel proteins are selectively expressed during experimental murine infection. Finally, we used differential display RT-PCR to identify transcripts of other differentially expressed $B$. burgdorferi genes. One gene (2.9-7lpB) identified with this technique belongs to a family of genes located on homologous 32- and 18-kb circular plasmids. The lipoprotein encoded by 2.9-7lpB was shown to be selectively expressed by chambergrown spirochetes and by spirochetes during experimental infection. Cultivation of $B$. burgdorferi in rat peritoneal implants represents a novel system for studying Lyme disease spirochetes in a mammalian host-adapted state. (J. Clin. Invest. 1998. 101:2240-2250.) Key words: host-adapted • chamber implants - ticks - Borrelia burgdorferi - outer surface protein
\end{abstract}

\section{Introduction}

Lyme disease (Lyme borreliosis) is a tick-borne multisystem infection caused by several species of spirochetes which have been grouped into the Borrelia burgdorferi sensu lato complex $(1,2)$. In North America, the B. burgdorferi sensu stricto geno-

Address correspondence to Dr. Justin D. Radolf, Division of Infectious Diseases, U.T. Southwestern Medical Center, 5323 Harry Hines Blvd., Dallas, TX 75235-9113. Phone: 214-648-6896; FAX: 214-6485476; E-mail: jradol@mednet.swmed.edu

Received for publication 21 November 1997 and accepted in revised form 15 March 1998.

J. Clin. Invest.

(C) The American Society for Clinical Investigation, Inc. 0021-9738/98/05/2240/11 \$2.00

Volume 101, Number 10, May 1998, 2240-2250

http://www.jci.org species is the most common etiologic agent of this disorder. The Lyme disease spirochete is maintained in nature via a complex enzootic cycle which typically involves wild rodents and ticks of the genus Ixodes $(3,4)$. To maintain this cycle, $B$. burgdorferi must adapt physiologically to two markedly different host milieus; during mammalian infection, the bacterium also presumably must express virulence determinants which are essential for disease pathogenesis. Consistent with these notions, there is now a substantial body of evidence that $B$. burgdorferi undergoes major alterations in antigenic composition as it cycles between its arthropod and mammalian hosts. In this regard, the reciprocal changes in outer surface protein $(\mathrm{Osp})^{1} \mathrm{~A}$ and OspC that occur during tick feeding have become a paradigm for differential gene expression by the Lyme disease spirochete (5-8). Other differentially expressed $B$. burgdorferi proteins described in recent years include EppA, p35, p37, the OspE homologue p21, the OspF homologues $\mathrm{BbK} 2.10$ and $\mathrm{pG}$, and Lp6.6. Of these, Lp6.6 is thought to be specific for the arthropod phase of the enzootic cycle (Schoeler, G.B., and S.K. Wikel, unpublished observations), whereas the others appear to be expressed exclusively during mammalian infection (9-14).

Environmental cues such as nutrient availability, $\mathrm{pH}$, osmolarity, $\mathrm{O}_{2}, \mathrm{CO}_{2}$, reactive oxygen and nitrogen compounds, inorganic ion concentrations, and temperature can influence the expression of bacterial virulence determinants $(15,16)$. In the case of $B$. burgdorferi, a transition from ambient to mammalian body temperature has been shown to induce the expression of OspC, OspE, and OspF $(5,17)$. Unidentified signals other than temperature also appear to modulate the expression of borrelial genes. For example, in contrast to OspC, expression of OspA and OspB is not affected by temperature shift (5). Moreover, transcript for p21 was not detected in experimentally infected mice until $21 \mathrm{~d}$ after infection; this time course is inconsistent with the regulation of the gene primarily by thermal stimuli (18). The appearance of new IgM antibodies and the expansion of the IgG response to borrelial antigens during human infection also suggest that diverse stimuli influence gene expression in the Lyme disease spirochete $(19,20)$.

The term host-adapted has been coined to designate the antigenic and structural changes which Lyme disease spirochetes undergo during and subsequent to tick transmission (6, 21-23). Because of the paucibacillary nature of Lyme disease and the fact that spirochetes isolated from infected tissues revert to the in vitro phenotype during cultivation, it has been difficult to study borreliae in the host-adapted state. An alter-

1. Abbreviations used in this paper: 2D-NEPHGE, two-dimensional nonequilibrium pH gel electrophoresis; BSKII, Barbour-StoennerKelly II; ddRT-PCR, differential display reverse transcriptase PCR; DMC, dialysis membrane chamber; GST, glutathione $S$-transferase; Osp, outer surface protein. 
native approach for obtaining host-adapted spirochetes is to use a chamber implant system modeled after those used previously to study other bacterial pathogens in vivo $(24,25)$. Other investigators have used chamber implant models to study various aspects of Lyme disease pathogenesis, however, the steel net or Teflon chambers implanted subcutaneously in these earlier reports were not used to study antigenic changes which occur in spirochetes during infection $(26,27)$. Recently, de Silva et al. (23) reported that Lyme disease spirochetes undergo host-adaptive changes during cultivation within plastic ring chambers implanted into the peritoneal cavities of mice; however, the small numbers of organisms obtained in this manner precluded subsequent antigenic analysis. To circumvent this problem, we cultivated borreliae within dialysis membrane chambers (DMCs) implanted intraperitoneally into rats. Our findings represent the first direct demonstration that the mammalian host environment induces global alterations in protein composition and gene expression within $B$. burgdorferi. Cultivation of $B$. burgdorferi in rat peritoneal implants has the potential to become a new model system for studying Lyme disease pathogenesis.

\section{Methods}

Bacterial strains and plasmids. Low-passage B. burgdorferi 297 that was originally isolated from the cerebrospinal fluid of a Lyme disease patient with meningitis (28) was obtained from Russell Johnson (University of Minnesota). All experiments were performed with spirochetes which had been passaged no more than three times in Barbour-Stoenner-Kelly II (BSKII) medium (29) after infectivity testing by low-dose $\left(10^{3}\right.$ borreliae) needle inoculation of 3-wk-old $\mathrm{C} 3 \mathrm{H} / \mathrm{HeJ}$ mice (Jackson Laboratory, Bar Harbor, ME). Spirochetes were cultivated in vitro at 23,34 , or $37^{\circ} \mathrm{C}$ after temperature shift from $23^{\circ} \mathrm{C}$ as described previously $(5,17)$.

Escherichia coli. E. coli DH5 $\alpha$ (GIBCO BRL, Gaithersburg, MD) was used for all transformation experiments. Strains and transformants were grown on yeast-tryptone agar or broth supplemented with the appropriate antibiotic. Plasmids pGEX-2T and pGEX-4T-2 (30) (Pharmacia LKB Biotechnology, Piscataway, NJ) were used for generating glutathione $S$-transferase (GST) fusion proteins. The pCRII vector (Invitrogen, San Diego, CA) was used for cloning differential display reverse transcriptase PCR (ddRT-PCR) products.

Implantation of DMCs. A Spectra/Por dialysis membrane (Spectrum Medical Industries Inc., Los Angeles, CA) with a mol wt cut-off of 5,000 was sterilized by boiling for $20 \mathrm{~min}$ in sterile water containing $5 \mathrm{mM}$ EDTA. Dialysis bags were allowed to cool in BSKII medium and tied at one end. Each bag was then filled with $5 \mathrm{ml}$ of BSKII medium containing $10^{3}$ in vitro-cultivated organisms from a midlogphase culture; the tubing was then tied and excess membrane was removed from both ends. 4-6-wk-old Sprague-Dawley rats (Harlan Sprague-Dawley Inc., Indianapolis, IN) were anesthetized by subcutaneous injection of a mixture of ketamine $(50 \mathrm{mg} / \mathrm{ml})$, xylazine $(5 \mathrm{mg} /$ $\mathrm{ml})$, and acepromazine $(1 \mathrm{mg} / \mathrm{ml})$ at a dose of $1 \mathrm{ml} / \mathrm{kg}$ of body weight. Using strict aseptic technique, DMCs were then implanted into the rat peritoneal cavities. In most experiments, DMCs were harvested $192 \mathrm{~h}$ after implantation. The outside of each chamber was washed extensively with sterile BSKII medium and then the contents were removed by syringe aspiration.

Analysis of B. burgdorferi growth kinetics. Duplicate 5-ml portions of BSKII medium, containing $10^{3}$ midlog-phase organisms, were incubated at 23,34 , or $37^{\circ} \mathrm{C}$ (after temperature shift from $23^{\circ} \mathrm{C}$ ). $16 \mathrm{DMCs}$ were implanted separately into the peritoneal cavities of rats as described above. At designated time points, implants were removed and spirochetes were harvested. Spirochetes were enumerated by darkfield microscopy using a Petroff-Hausser counting chamber (Hausser
Scientific Co., Horsham, PA). Numbers of spirochetes at each time point were expressed as the average of duplicate samples.

Comparison of infectivity of in vitro- and DMC-cultivated spirochetes. Spirochetes cultivated in BSKII medium at $34^{\circ} \mathrm{C}$ or $8 \mathrm{~d}$ after implantation into DMCs were quantitated using a Petroff-Hausser (Hausser Scientific Co.) counting chamber and then injected intradermally into groups of five $\mathrm{C} 3 \mathrm{H} / \mathrm{HeJ}$ mice at doses of $10,10^{2}, 10^{3}$, and $10^{4}$ spirochetes per mouse. $2 \mathrm{wk}$ after the challenge, mice were tested for infection by culturing ear-punch biopsies at $34^{\circ} \mathrm{C}$ in BSKII medium containing amphotericin $B(2.5 \mu \mathrm{g} / \mathrm{ml})$ and rifampin $(50 \mu \mathrm{g} / \mathrm{ml})$ (31).

Cloning of the ospE and p21 genes from B. burgdorferi 297 and construction of GST fusion proteins. To clone the ospE gene from B. burgdorferi 297, a probe was PCR-amplified from strain 297 genomic DNA using forward and reverse primers (5' $5^{\prime}$ TGTAAAAATCATACTTTATATGATGG-3' and 5'-CTCCTGTATTTTTAACTTCTA-3', respectively) based upon the previously reported B. burgdorferi N40 ospE sequence (32). The resulting PCR product was gelpurified, labeled with $\left[\alpha-{ }^{32} \mathrm{P}\right] \mathrm{dCTP}$ using the Boehringer Mannheim (Indianapolis, IN) random primer DNA labeling kit, and used to screen a strain 297 genomic library constructed in lambda ZapII (12). Clones containing the strain 297 p21 gene were identified from the same library using an oligonucleotide (5'-GCAAAGTAATAATGAGTTAAAAGTTAAGCAAAG-3') derived from the previously reported N40 p21 sequence (11). The p21 oligonucleotide probe was labeled with $\left[\gamma^{-32} \mathrm{P}\right] \mathrm{dATP}$ using the Boehringer Mannheim 5' end labeling kit.

Hybridizations were carried out overnight in $2 \times$ Denhardt's solution, $6 \times \mathrm{SSC}(1 \times \mathrm{SSC}$ is $0.15 \mathrm{M} \mathrm{NaCl}$ and $0.015 \mathrm{M}$ sodium citrate), $1 \mathrm{mM}$ EDTA, and $100 \mu \mathrm{g} / \mathrm{ml}$ of sonicated salmon sperm DNA at either $65^{\circ} \mathrm{C}$ (ospE probe) or $42^{\circ} \mathrm{C}$ (p21 probe) in a rotating oven (Robbin's Scientific Corp., Sunnyvale, CA). After hybridization, the nitrocellulose filters were washed four times for $30 \mathrm{~min}$ each in $0.2 \times \mathrm{SSC}$ (ospE) or $2 \times$ SSC (p21) containing $0.1 \%$ SDS at a temperature $2^{\circ} \mathrm{C}$ above the hybridization temperatures for the respective probes. Filters then were subjected to autoradiography at $-70^{\circ} \mathrm{C}$ for $24-48 \mathrm{~h}$.

OspE- and p21-GST fusions were generated by directionally cloning PCR-amplified DNA fragments encoding the mature forms of each protein into the BamHI and SalI sites ( $o s p E)$ or the BamHI and EcoRI sites $(p 21)$ of the fusion vectors pGEX-4T-2 and pGEX-2T, respectively. The DNA fragments were generated using purified plasmids encoding the strain 297 osp $E$ or $p 21$ genes as templates and the following forward and reverse primers: 5'-CGCGGATCCTGTAAAAATCATACTTTATATGATGGG-3' (BamHI site plus nucleotides 58-84) and 5'-CACCGTCGACCTCCTGTATTTTTAACTTCTA-3' (SalI site plus nucleotides complementary to bases 537517) for $o s p E$ and 5'-GCGGGATCCTGCAAAATTCATACTTCATATG-3' (BamHI site plus nucleotides 58-79) and 5'-GCGGAATTCCTTCTATTTTAAATTTTTTTTAAG-3' (EcoRI site plus nucleotides complementary to bases 561-538) for $p 21$. 2.9-7LpA- and 2.9-7LpB-GST fusion proteins were generated by directionally cloning PCR-amplified DNA fragments encoding the mature forms of each protein into the BamHI and EcoRI sites of pGEX-2T. The DNA fragments were generated using purified plasmid encoding the strain 297 2.9-7lpA and 2.9-7lpB genes (33) as template and the following forward and reverse primers: 5'-GGGGATCCTGCGCTGCTAATGATACACAG-3' (BamHI site plus nucleotides 2205-2225) and 5'GGGAATTCCCTTTTTCTTATGACTAATTATTGC-3' (EcoRI site plus nucleotides complementary to bases 2596-2572) for 2.9-7lpA and 5'-GGGGATCCTGCAATGCTAATGATAATGATAC-3' (BamHI site plus nucleotides 2655-2677) and 5'-GGGAATTCGAGAAATGTTTTTAGTTTTGCC-3' (EcoRI site plus nucleotides complementary to bases 3244-3223) for 2.9-7lpB. Construction of the recombinant $2.9-4 \mathrm{Lp}$-GST fusion protein has been described previously (33). The resulting GST fusions were purified by affinity chromatography on an agarose-glutathione matrix according to manufacturer's instructions (Pharmacia LKB Biotechnology). For the production of antiserum, the OspE, p21, 2.9-7LpA, and 2.9-7LpB portion of the re- 
spective GST fusion proteins were cleaved with thrombin from the GST moiety while still bound to the agarose-glutathione matrix (34). Thrombin was subsequently removed using benzamidine Sepharose ${ }^{\circledR}$ $6 \mathrm{~B}$ according to the manufacturer's instructions (Pharmacia LKB Biotechnology).

Immunological reagents. To generate polyclonal antisera directed against OspE, p21, 2.9-7LpA, and 2.9-7LpB, 4-6-wk-old Sprague-Dawley rats were primed by intraperitoneal injection with $50 \mu \mathrm{g}$ of the purified proteins in a 1:1 mixture of Freund's complete adjuvant. 4 wk later, the animals were boosted twice at 3-wk intervals by the same route with $30 \mu \mathrm{g}$ of protein in Freund's incomplete adjuvant. Sera from B. burgdorferi-297-infected $\mathrm{C} 3 \mathrm{H} / \mathrm{HeJ}$ mice were obtained $1,2,4,8,16$, and $52 \mathrm{wk}$ after syringe inoculation with $10^{3}$ spirochetes; specimens from each time point were pooled.

mAbs directed against BbK2.10 (12H6-46) and OspF (10D7-42) were generated using recombinant forms of the respective proteins generated as GST fusions $(12,35)$. Female Balb/c mice were injected intraperitoneally with $20 \mu \mathrm{g}$ of purified protein in a 1:1 mixture of Freund's complete adjuvant and boosted three times at 1-mo intervals with $10 \mu \mathrm{g}$ of protein in a 1:1 mixture with Freund's incomplete adjuvant. The final immunization was administered intravenously with $10 \mu \mathrm{g}$ of protein in PBS (pH 7.4). Mice were killed $3 \mathrm{~d}$ later and their spleens were removed for the production of hybridomas. Hybridomas were screened by ELISA using the appropriate recombinant protein, and their specificities were confirmed by immunoblot analysis. mAb 240.7, which is directed against Lp6.6 $(14,36)$, was provided by Laura Katona and Gail Habicht (SUNY at Stony Brook, Stony Brook, NY). mAb 9B12, used as a negative control for the indirect immunofluorescence analyses (see below), is specific for a $34-\mathrm{kD}$ lipoprotein of Treponema pallidum (37). mAbs 9A4-40, 14D2-27, and 1H6-33, which are directed against a 22-kD polypeptide (p22), OspA, and flagellin, respectively, were generated by immunizing a Balb/c mouse with B. burgdorferi B31 whole-cell lysates. All mAbs were of the $\mathrm{IgG}_{1}$ isotype.

Indirect immunofluorescence. 10- $\mu$ l droplets from cultures containing midlog-phase organisms cultivated in vitro at $34^{\circ} \mathrm{C}$ or harvested from DMCs $7 \mathrm{~d}$ after inoculation were applied to chromic acid-washed glass slides and allowed to air dry. Slides were fixed by immersion in acetone for $10 \mathrm{~min}$ and subsequently incubated for $1 \mathrm{~h}$ with a 1:100 dilution of mAb 14D2-27 (anti-OspA) hybridoma supernatant or a 1:500 dilution of affinity purified mAb 240.7 (anti-Lp6.6). Additional slides were incubated with 1:100 dilutions of mAb 1H6-33 (antiflagellin) or mAb 9B12 (anti-T. pallidum 34-kD lipoprotein) hybridoma supernatants to serve as positive and negative controls, respectively. After washing, each slide was then incubated with a 1:1,000 dilution of fluorescein isothiocyanate-conjugated goat antimouse IgG (Sigma Chemical Co., St. Louis, MO). 150 organisms on each slide were analyzed for fluorescence.

SDS-PAGE and immunoblot analysis. Samples were boiled for $5 \mathrm{~min}$ in a final sample buffer consisting of $62.5 \mathrm{mM}$ Tris- $\mathrm{HCl}(\mathrm{pH}$ 6.8 ), $10 \%$ glycerol, $5 \%$ vol/vol 2 -mercaptoethanol, and $0.001 \%$ bromophenol blue before electrophoresis through $2.4 \%$ stacking and $12.5 \%$ separating gels. Gels were then either stained with silver according to the procedure of Morrissey (38) or transferred electrophoretically to $0.2-\mu \mathrm{M}$-pore size nitrocellulose (Schleicher and Schuell, Keene, NH) for immunoblotting. Immunoblots were incubated with 1:1,000 dilutions of sera or with 1:100 dilutions of hybridoma supernatants after which the membranes were washed and then incubated for 45 min with a 1:1,000 dilution of rabbit anti-rat IgG plus IgM (Zymed, South San Francisco, CA) or rabbit anti-mouse IgG-horseradish peroxidase (HRP) conjugate. Immunoblots were developed using 4-chloro-1-napthol as the substrate or by enhanced chemiluminescence (Amersham, Arlington Heights, IL) after exposure to film for $30 \mathrm{~s}$.

Two-dimensional nonequilibrium $\mathrm{pH}$ gel electrophoresis $(2 \mathrm{D}$ $N E P H G E$ ). Proteins in whole-cell lysates were quantitated using the Bio-Rad Laboratories protein assay (Hercules, CA) which is based upon the Bradford dye-binding procedure (39). 2D-NEPHGE was performed as described previously (40). Whole-cell lysates were subjected to first-dimension NEPHGE for $5 \mathrm{~h}$ at $400 \mathrm{~V}$ in $11-\mathrm{cm}$ tube gels consisting of $4 \% \mathrm{pH} \mathrm{5-7}$ and $1 \% \mathrm{pH} 3.5-10$ ampholines (Bio-Rad Laboratories). For the second dimension, tube gels were overlaid on top of $2.4 \%$ stacking and $12.5 \%$ separating SDS-polyacrylamide slab gels. Apparent isoelectric points were determined by adding isoelectric point standards (Bio-Rad Laboratories) to one tube gel and subjecting it to first- and second-dimension electrophoresis under the same conditions.

$d d R T-P C R$. Total RNA was isolated from spirochetes harvested at peak cell density from cultures incubated in vitro or within DMC implants using the Qiagen (Chatsworth, CA) maxiprep column according to the manufacturer's protocol. Extracted RNA $(10 \mu \mathrm{g})$ was incubated with $10 \mathrm{U}$ of DNase (Promega Corp., Madison, WI) at $37^{\circ} \mathrm{C}$ for $1 \mathrm{~h}$. The RNA was extracted once with phenol/chloroform and precipitated. The final pellets were resuspended in $30 \mu \mathrm{l}$ of diethyl pyrocarbonate-treated water containing $1 \mu \mathrm{l}$ of RNasin (Promega Corp.). cDNA was prepared by incubating $2 \mu \mathrm{g}$ of DNasetreated RNA with avian myeloblastosis virus reverse transcriptase (Promega Corp.) and random hexamers using the Promega reverse transcription system according to the manufacturer's instructions. The resulting cDNA was diluted to $200 \mu \mathrm{l}$ with sterile water and $5 \mu \mathrm{l}$ was used for subsequent PCR analysis. PCR was performed in $20-\mu 1$ reactions containing $1 \mu \mathrm{l}\left[\alpha^{-35} \mathrm{~S}\right] \mathrm{dATP}$ (Amersham), $2 \mu \mathrm{l} 10 \times$ buffer (100 mM Tris-Cl, $\mathrm{pH} 8.4,500 \mathrm{mM} \mathrm{KCl}, 15 \mathrm{mM} \mathrm{MgCl}$ ), $1.6 \mu \mathrm{l}$ of $25-$ $\mu \mathrm{M}$ dNTPs, $2 \mu \mathrm{l}$ of each arbitrary primer, and $0.2 \mu \mathrm{l}$ of AmpliTaq (Perkin-Elmer, Foster City, CA). PCR reactions were subsequently overlaid with $50 \mu$ l of mineral oil and subjected to the following PCR parameters: $94^{\circ} \mathrm{C}$ for $30 \mathrm{~s}, 40^{\circ} \mathrm{C}$ for $2 \mathrm{~min}$, and $72^{\circ} \mathrm{C}$ for $30 \mathrm{~s}$ for $40 \mathrm{cy}-$ cles with a final extension at $72^{\circ} \mathrm{C}$ for $5 \mathrm{~min}$. The PCR reactions were performed a minimum of two times to ensure the reproducibility of the differentially displayed products analyzed. The following oligonucleotides were used in various combinations for PCR: (1) 5'-GAACACGGTCCTCAATGCTC-3', (2) 5'-TCCTTCTCCATTTTCATCAG-3', (3) GTGGCAGATCAACCATGACC-3', (4) 5'-CCCAAGGGCACAACCATATT-3', (5) 5'-TTATTGCAGACCTGGATCCA-3', and (6) 5'-GTGTAAGGCATGTGGCTCCT-3' (primers 2 and 3 were used for the differential display pattern [see Fig. $8 \mathrm{~A}$ ]). PCR products were subjected to electrophoresis in a $6 \%$ denaturing polyacrylamide sequencing gel and exposed to film overnight. The developed autoradiographs were aligned with the gel and differentially expressed products were excised. The gel slices were soaked in $100 \mu \mathrm{l}$ of sterile water and boiled for $10 \mathrm{~min}$. The gel slice was then removed and the eluted DNA was ethanol-precipitated. Each differentially expressed product was then reamplified using the same primer set used in the original PCR. PCR products generated in this manner were cloned into the pCRII vector for subsequent nucleotide sequence analysis. To determine the genomic location of ddRT-PCR products which were not homologous to sequences deposited in the gene databases, B. burgdorferi 297 genomic DNAs were separated by pulsed-field gel electrophoresis and hybridized with specific oligonucleotides after transfer to nylon membranes as described previously (12).

RT-PCR of flagellin, ospA, and 2.9-7lpA/B from B. burgdorferi cultivated in vitro or within DMC implants. cDNA was prepared from borreliae cultivated in vitro or within DMC implants as described above. Three sets of specific upstream and downstream primers were used to amplify: flagellin (5'-GATTATATCAATCATAATACATCAGC-3' and 5'-TCTAAGCAATGACAAAACATATTGG-3'), ospA (5'-TGTAAGCAAAATGTTAGCAGCCTT-3' and 5'-TTATTTTAAAGCGTTTTTAATTTC- ${ }^{\prime}$ ), and 2.9-7lpA/B (5'-TGCGCTGCTAATGATACACAG-3' and 5'-GAGAAATGTTTTTAGTTTTGCC- $3^{\prime}$ ) using denaturing, annealing, and extension temperatures of 94,54 , and $72^{\circ} \mathrm{C}$, respectively, for $75 \mathrm{~s}$ at each step for 35 cycles. The predicted sizes of the amplification products were $1006 \mathrm{bp}$ (flagellin), $774 \mathrm{bp}$ (ospA), and $1039 \mathrm{bp}$ (2.9-7lpA/B).

Nucleotide sequence analysis. Nucleotide sequencing was performed using an automated DNA sequencer (model 373A; Applied 
Biosystems Inc.; Foster City, CA) and the PRISM ${ }^{\mathrm{TM}}$ ready reaction DyeDeoxy ${ }^{\mathrm{TM}}$ Terminator cycle sequencing kit according to the manufacturer's instructions (Applied Biosystems Inc.). Computer analysis of the nucleotide and deduced amino acid sequences was performed using the MacVector version 6.0.1 (Oxford Molecular Group, Oxford, England) or the University of Wisconsin Genetics Computer Group version 8.1 (41) software programs.

\section{Results}

B. burgdorferi 297 replicates and alters its antigenic composition during growth within DMCs. We first asked whether a small inoculum of low-passage B. burgdorferi 297 would survive and replicate within DMCs implanted into the peritoneal cavities of rats. Accordingly, in preliminary experiments, DMCs containing a total of $10^{3}$ organisms in $5 \mathrm{ml}$ of BSKII medium were implanted into two rats. When the chambers were removed $7 \mathrm{~d}$ later, it was noted that neither chamber had induced an obvious inflammatory reaction and that the fluids from both contained extremely motile spirochetes which were readily detectable by dark-field microscopy (data not shown). To determine whether the antigenic composition of the spirochetes was altered by growth within the DMCs, spirochetes grown in chamber implants or BSKII medium were spotted onto slides for indirect immunofluorescence analysis of OspA, a lipoprotein known to be downregulated in vivo (i.e., during mammalian infection). As shown in Fig. 1, in vitro-cultivated borreliae fluoresced intensely after incubation with an OspAspecific $\mathrm{mAb}$, whereas none of the organisms analyzed from DMCs were immunoreactive. We also assessed expression in the two bacterial populations of an abundant 6.6-kD lipoprotein (designated Lp6.6) which, like OspA, has been reported to be downregulated during mammalian infection (14). The in vitro-cultivated borreliae reacted strongly with the Lp6.6-specific $\mathrm{mAb}$, whereas no fluorescence was observed with spirochetes from the chambers (Fig. 1). Control slides were incubated with a mAb specific for B. burgdorferi flagellin or an isotype-matched control $\mathrm{mAb}$ directed against a 34-kD T. pallidum lipoprotein (37). As expected, all organisms reacted

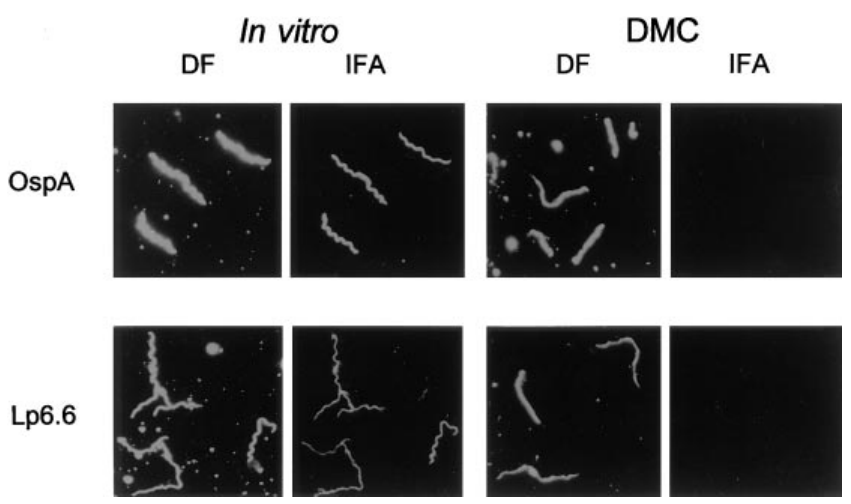

Figure 1. B. burgdorferi 297 cultivated within peritoneal chamber implants does not express OspA or Lp6.6. Spirochetes grown in vitro or within DMCs were incubated with $\mathrm{mAbs}$ specific for OspA (14D227) and Lp6.6 (240.7) followed by a FITC-conjugated secondary antibody before visualization by dark-field $(D F)$ or fluorescence (IFA) microscopy. For each sample, 150 organisms were analyzed. Total magnification in all photographs is 1,250. strongly with the antiflagellin $\mathrm{mAb}$, whereas none reacted with the $T$. pallidum-specific antibody (data not shown).

Growth kinetics of B. burgdorferi within DMCs. Many bacterial polypeptides are expressed in a growth phase-dependent manner (42-45); growth phase-dependent expression of B. burgdorferi lipoproteins also has been demonstrated (46). Because studies to assess differences in the protein composition of in vitro- and chamber-grown organisms could be confounded by a failure to control for growth phase, we next determined the growth kinetics of DMC- and in vitro-cultivated spirochetes. In addition to cultures incubated at $34^{\circ} \mathrm{C}$, growth curves were also determined for cultures incubated at 23 and $37^{\circ} \mathrm{C}$ (after temperature shift from $23^{\circ} \mathrm{C}$ ), in the expectation that their inclusion in subsequent analyses would help us to identify proteins regulated primarily by the higher ambient temperature of the rat peritoneal cavity $\left(\sim 37^{\circ} \mathrm{C}\right)(47)$.

Beginning $6 \mathrm{~d}$ after implantation, DMCs from eight pairs of rats were harvested at selected time points and enumerated by dark-field microscopy in parallel with identical cultures incubated at 23,34 , and $37^{\circ} \mathrm{C}$ (temperature-shifted). For all four populations, motility was $>95 \%$ through peak cell density but declined steadily during the remainder of the 10 -d observation period (data not shown). Aside from the anticipated temperature-related differences in growth rates, the growth curves of the in vitro-cultivated organisms were quite similar (Fig. 2). On the other hand, three principal differences were noted between the growth curves of in vitro- and DMC-grown spirochetes: $(a)$ the cell densities of DMC-cultivated borreliae were considerably higher at the earlier time points (144-192 h), (b)

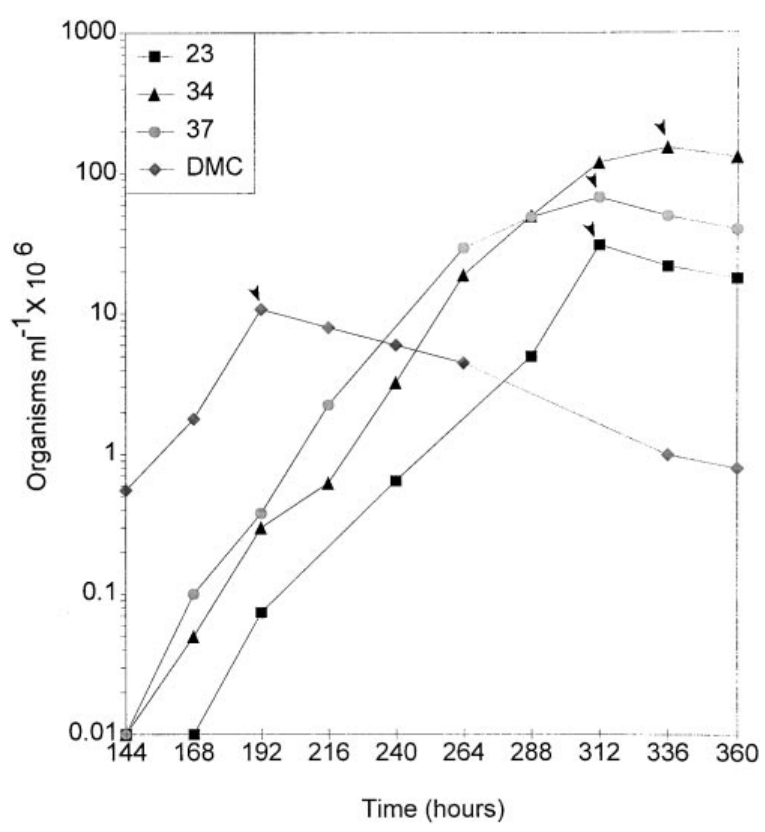

Figure 2. Growth kinetics of B. burgdorferi 297 cultivated in vitro or within DMCs. Spirochetes cultivated in BSKII medium at 23 (squares), 34 (triangles), or $37^{\circ} \mathrm{C}$ (circles) after temperature shift or within DMCs (diamonds) were enumerated by dark-field microscopy over a 15 -d period after inoculation. In all four cultures, 5 -ml volumes were inoculated with $10^{3}$ midlogarithmic-phase organisms. Data points represent the means of duplicate samples. The arrows indicate the time points at which organisms were harvested for subsequent analyses. 
the peak cell density reached by the DMC-cultivated organisms was considerably lower, and (c) DMC-cultivated spirochetes stopped replicating at a much earlier time point. An interesting qualitative difference was also noted in that the motility of chamber-grown spirochetes was considerably more vigorous. In subsequent analyses, borreliae were harvested at peak cell density (Fig. 2, arrows) to maximize the yields of motile spirochetes from the DMCs. To confirm that organisms cultivated in DMCs remained virulent, groups of five mice were inoculated with $10,10^{2}, 10^{3}$, or $10^{4}$ spirochetes from DMCs or organisms grown in BSKII medium, and ear-punch biopsies were obtained $2 \mathrm{wk}$ after inoculation. The $\mathrm{ID}_{50}$ values were determined to be $\sim 10^{2}$ for spirochetes cultivated under either condition.

Polypeptide profiles of in vitro- and DMC-cultivated spirochetes. We next used SDS-PAGE to compare the protein constituents of in vitro- and DMC-cultivated spirochetes. With the exception of OspC, which was poorly expressed during growth at $23^{\circ} \mathrm{C}$, the polypeptide profiles of the in vitro-cultivated organisms were virtually identical (Fig. 3). In contrast, differences between DMC- and in vitro-cultivated borreliae were readily apparent. The most striking changes were the apparent absence of OspA and OspB and the dramatic increase of OspC in the DMC-cultivated spirochetes (Fig. 3, lane 3).

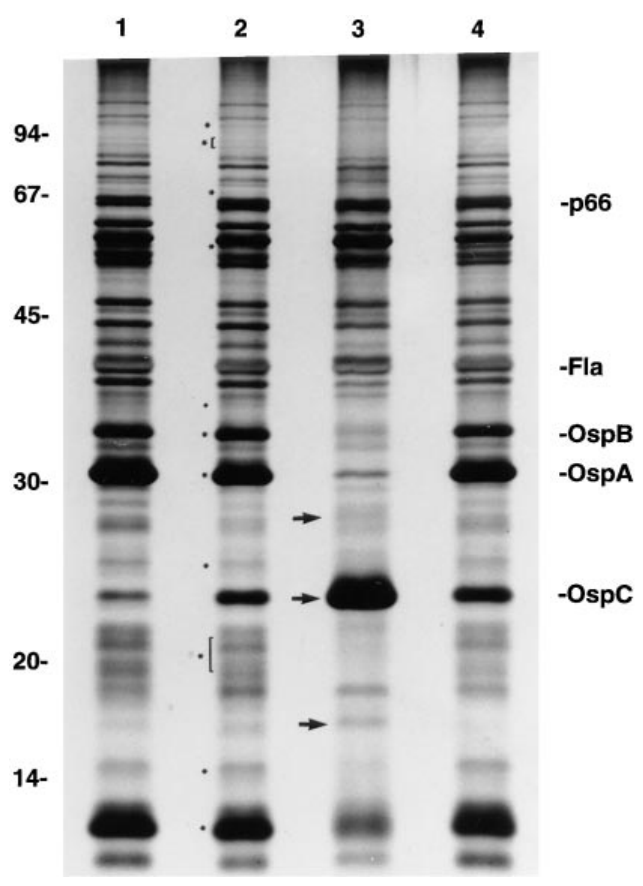

Figure 3. SDS-PAGE of B. burgdorferi 297 grown in vitro or within DMCs. Whole-cell lysates (15 $\mu \mathrm{g}$ of protein per lane) from spirochetes grown in vitro at $23^{\circ} \mathrm{C}$ (lane 1 ), after temperature-shift at $37^{\circ} \mathrm{C}$ (lane 2), within chamber implants (lane 3 ), or in vitro at $34^{\circ} \mathrm{C}$ (lane 4 ) were separated by SDS-PAGE and stained with silver. Asterisks alongside lane 2 indicate polypeptides which were identified in in vitro-grown spirochetes but were absent or dramatically downregulated in chamber-grown spirochetes. Arrows designate proteins either dramatically upregulated or observed only in chamber-cultivated organisms. Well characterized borrelial proteins are indicated on the right and molecular mass markers in kilodaltons are shown on the left.
Other differences were also noted, the majority of which involved polypeptides that were either selectively expressed or upregulated during in vitro cultivation (Fig. 3, lane 2, asterisks); these were most apparent in the $18-$ to $21-\mathrm{kD}$ range. Three proteins that appeared to be unique or dramatically upregulated in chamber-grown spirochetes (Fig. 3, lane 3, arrows) were also identified. To determine whether the protein alterations which occurred during cultivation in chambers were reversible, DMC-cultivated spirochetes were diluted into BSKII medium and incubated at $37^{\circ} \mathrm{C}$ in vitro. The polypeptide profile of these organisms was identical to that of spirochetes which had been passaged only in vitro (data not shown).

$2 D-N E P H G E$ analysis of in vitro- and DMC-cultivated spirochetes. The increased resolution afforded by $2 \mathrm{D}-\mathrm{NEPHGE}$ was used to further compare the protein constituents of in vitro- and chamber-grown spirochetes. Borreliae cultivated at $34^{\circ} \mathrm{C}$ contained only a single polypeptide not present in the temperature-shifted spirochetes (Fig. $4 \mathrm{~A}$, asterisk). In con-

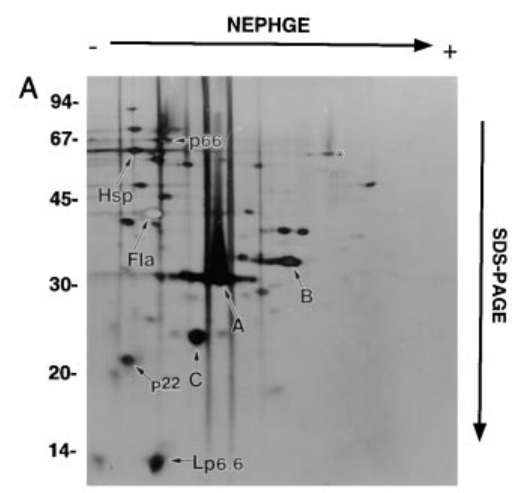

Figure 4. 2D-NEPHGE of B. burgdorferi 297 cultivated in vitro or in DMCs. Whole-cell lysates $(25 \mu \mathrm{g}$ of protein per gel) from spirochetes cultivated in vitro at $34^{\circ} \mathrm{C}(A)$, after temperature shift at $37^{\circ} \mathrm{C}(B)$, or within DMCs $(C)$ were separated by NEPHGE in the first dimension, $12.5 \%$ SDS-PAGE in the second dimension, and then stained with silver. The directions of separation in the first and second dimensions (NEPHGE and SDS-

$P A G E$, respectively) are indicated. The acidic and basic ends of the gels are indicated by - and + , respectively. Borrelial proteins Lp6.6, p22, OspC, OspA, OspB, flagellin, Hsp60, and p66 are indicated by $L p 6.6, p 22, C$, $A, B, F l a, H s p$, and $p 66$, respectively. In $A$, a polypeptide which is unique to organisms cultivated in vitro at $34^{\circ} \mathrm{C}$ is indicated by the asterisk. In $B$, temperature-regulated polypeptides are indicated with arrowheads; an asterisk alongside an arrowhead indicates a temperature-induced protein which was not observed in chamber-grown organisms. In $C$, proteins which are differentially expressed in chamber-grown spirochetes compared to temperature-shifted organisms are indicated by arrowheads. Molecular mass markers in kilodaltons are shown on the left. 
trast, temperature-shifted organisms contained 11 proteins not present or poorly expressed in organisms grown at $34^{\circ} \mathrm{C}$ (Fig. 4 $B$, arrowheads), four of which were also present in DMC-cultivated borreliae. DMC-cultivated spirochetes contained at least 12 proteins which were absent or poorly expressed by temperature-shifted organisms (Fig. 4 C, arrowheads). Most notable in this regard was a cluster of proteins in the vicinity of OspC which indicated that the dramatic increase in OspC observed by SDS-PAGE (Fig. 3) was partly due to the comigration of multiple polypeptides. At least eight proteins (in addition to OspA and OspB) were absent or downregulated in DMC-cultivated borreliae. One of these was identified as Lp6.6 on the basis of its reactivity with mAb 240.7 (Fig. 4, $A$ and $B$ ). Lastly, seven of the polypeptides upregulated due to temperatureshift were absent from DMC-cultivated organisms (Fig. $4 \mathrm{~B}$, asterisks).

To confirm that the proteins unique to DMC-cultivated spirochetes are also expressed during infection, lysates separated by 2D-NEPHGE were probed with sera collected from mice 16 wk after low-dose needle inoculation with $B$. burgdorferi 297. As shown in Fig. 5, only minor differences were noted
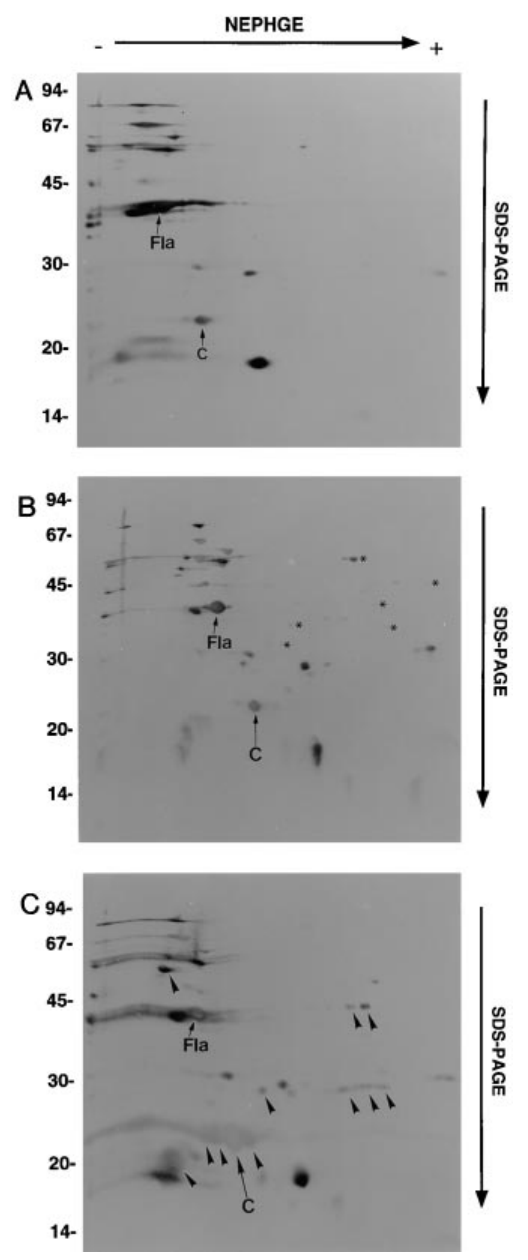

Figure 5. DMC-cultivated spirochetes differentially express antigens recognized by sera from mice chronically infected with $B$. burgdorferi 297 . Whole-cell lysates $(25 \mu \mathrm{g}$ of protein per gel) from spirochetes cultivated in vitro at $34^{\circ} \mathrm{C}(A)$, after temperature-shift at $37^{\circ} \mathrm{C}(B)$, or within DMCs $(C)$ were separated by NEPHGE in the first dimension, $12.5 \%$ SDS-PAGE in the second dimension, and then blotted to nitrocellulose membranes. The directions of separation in the first and second dimensions (NEPHGE and $S D S-P A G E$, respectively) are indicated. The acidic and basic ends of the gels are indicated by - and + , respectively. Membranes were incubated with 1 : 1,000 dilutions of pooled sera obtained from five $\mathrm{C} 3 \mathrm{H} / \mathrm{HeJ}$ mice 16 wk after needle inoculation with $10^{3} \mathrm{~B}$. burgdorferi 297. OspC and flagellin are indicated by $C$ and Fla, respectively. In $B$, antigens detected only in the temperature-shifted organisms are indicated by asterisks. In $C$, antigens detected only in chamber-cultivated organisms are indicated with arrowheads. Molecular mass markers in kilodaltons are shown on the left. between the immunoblot results obtained with spirochetes cultivated at $34^{\circ} \mathrm{C}$ and temperature-shifted organisms (Fig. 5, $A$ and $B$ ). Spirochetes grown within the chamber implants, on the other hand, expressed at least 11 antigens that were not detected in in vitro- cultivated borreliae (Fig. 5 C, arrowheads); the most obvious differences corresponded to the complex of polypeptides near OspC in the silver-stained 2D-NEPHGE gel (Fig. $4 C$ and Fig. $5 C$ ). Interestingly, the DMC-cultivated spirochetes lacked at least six antigens detected in the temperature-shifted organisms (Fig. 5 B, asterisks).

Identification of differentially expressed antigens by immunoblot analysis. Immunoblot analysis with specific antibodies was performed next to further define antigenic differences between in vitro- and DMC-grown borreliae. Here we focused on members of the OspE and OspF lipoprotein family in light of recent findings that $(a)$ expression of $\mathrm{OspE}$ and $\mathrm{OspF}$ is upregulated by temperature shift (17) and (b) B. burgdorferi isolates contain OspE and OspF homologues which are selectively expressed during infection $(11,12,18)$. Protein assay and reactivity with an antiflagellin $\mathrm{mAb}$ (Fig. 6) confirmed, at the outset, that the lysates contained equivalent amounts of protein.

OspE was expressed at similar levels by in vitro- and DMCcultivated organisms; as expected, a considerably smaller amount of this antigen was expressed by spirochetes cultivated at $23^{\circ} \mathrm{C}$ (Fig. 6). In contrast, p21 was not detected in any of the in vitro-grown organisms, including those which had been temperature shifted; however, it was detected in lysates from chamber-grown spirochetes (Fig. 6). B. burgdorferi 297 grown in vitro at $34^{\circ} \mathrm{C}$ expresses $\mathrm{OspF}$ and a highly similar polypeptide, designated BbK2.11 (12). Expression of both of these proteins was markedly enhanced by temperature shift, while even greater amounts were detected in chamber-grown spirochetes. BbK2.10, an OspF homologue expressed only during infection (12), was, as expected, not detected in organisms cultivated in vitro; somewhat surprisingly, however, this antigen

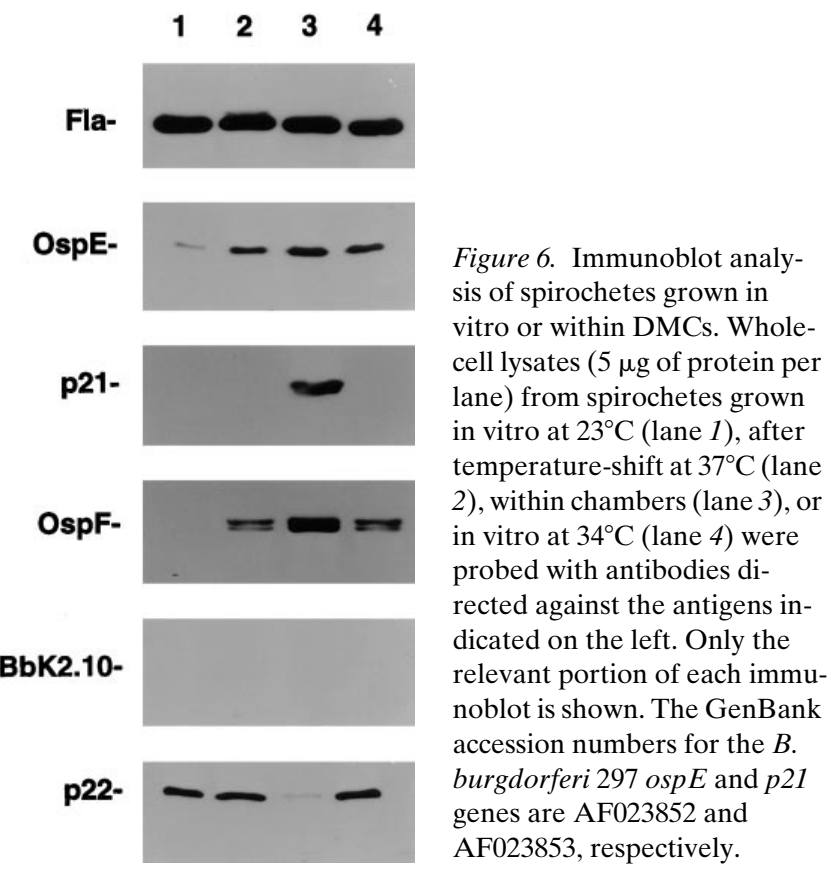


was not detected in spirochetes cultivated in chambers (Fig. 6). We also probed the lysates with a mAb directed against a recently identified 22-kD borrelial polypeptide (p22). This antigen was expressed at similar levels by the in vitro-grown borreliae but was barely detected in chamber-grown spirochetes (Fig. 6). This protein was subsequently found to correspond to a prominent silver-stained polypeptide which was observed only in the 2D-NEPHGE gels of in vitro-cultivated organisms (Fig. 4).

2D-NEPHGE immunoblot analysis was performed next to determine whether the enhanced reactivity of the OspF mAb with DMC-cultivated spirochetes was due to the expression of OspF-related proteins not resolved by conventional SDSPAGE. As shown in Fig. 7, borreliae cultivated in vitro at $34^{\circ} \mathrm{C}$ expressed two OspF mAb-reactive polypeptides whose isoelectric points (5.8 and 8.3) corresponded to those calculated for BbK2.11 and OspF (5.85 and 8.31, respectively) (12). Lysates from the temperature-shifted borreliae contained greater amounts of these two antigens along with a small amount of a third mAb-reactive polypeptide which was slightly more basic than BbK2.11. The DMC-cultivated spirochetes expressed all three mAb-reactive proteins as well as a unique fourth polypeptide (particularly impressive were the increased amounts of these four proteins). In contrast to OspF, similar amounts of OspE were detected when all three cell lysates were probed with the OspE-specific antiserum (data not shown). For comparison purposes, the lysates also were probed with the OspA $\mathrm{mAb}$ used for the prior indirect immunofluorescence analysis.

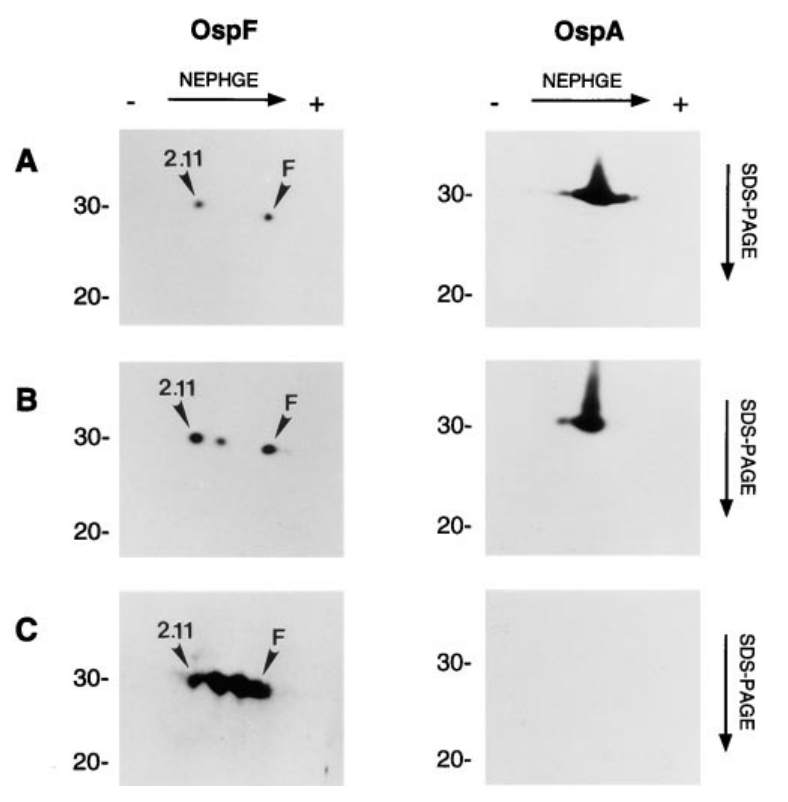

Figure 7. Differential expression of OspF-related proteins. Wholecell lysates ( $25 \mu \mathrm{g}$ of protein per gel) from spirochetes cultivated in vitro at $34^{\circ} \mathrm{C}(A)$, after temperature-shift at $37^{\circ} \mathrm{C}(B)$, or within DMCs $(C)$ were separated by $2 \mathrm{D}-\mathrm{NEPHGE}$ and probed with $\mathrm{mAbs}$ directed against OspF or OspA. The directions of separation in the first and second dimensions ( $N E P H G E$ and $S D S-P A G E$, respectively) are indicated. The acidic and basic ends of the gels are denoted by - and + , respectively. Only the relevant portion of each immunoblot is shown. BbK2.11 (2.11) and $\operatorname{OspF}(F)$ are indicated in each of the $\mathrm{OspF} \mathrm{mAb}$ immunoblots. Molecular mass markers in kilodaltons are shown on the left.
As before, OspA was abundant in organisms cultivated in vitro at 34 or $37^{\circ} \mathrm{C}$ but was not detected in DMC- cultivated spirochetes (Fig. 7).

Identification of selectively expressed B. burgdorferi genes with ddRT-PCR. Lastly, we used a PCR-based technique (ddRT-PCR) to determine whether cultivation of spirochetes within DMCs induced changes in gene expression which might not have been apparent from the protein electrophoresis studies described above. With this method, RNA is reverse-transcribed and the resulting cDNAs are PCR-amplified with random oligonucleotide primers; comparison of the amplicons obtained with individual primer pairs from different cDNA pools enables one to identify differentially expressed genes. When this technique was applied to cDNAs derived from in vitro- and chamber-grown spirochetes, it was noted that some PCR products were approximately equal in abundance, whereas others appeared to be unique or highly enriched in one of the two pools (Fig. $8 A$ ). 11 randomly chosen PCR products (three from in vitro- and eight from DMC-cultivated spirochetes) were reamplified, cloned, and sequenced. The resulting nucleotide and deduced amino acid sequences were then used to search the GenBank database and the B. burgdorferi B31 chromosome and plasmid sequences which are currently available (48).

No matches were found in the gene databases for 8 of the 11 sequences. Southern hybridization of DNAs separated by pulsed-field gel electrophoresis revealed that all eight were encoded on extrachromosomal elements (data not shown). Two (one each from the in vitro- and DMC-cultivated organisms) matched exactly sequences from the B. burgdorferi B31 chromosome. The first, a 291-bp sequence amplified from in vitrocultivated borreliae, was part of an open reading frame encoding a homologue of the glycolytic enzyme phosphoglucoisomerase, which corresponds to the gene designated $B b 730$ (48) from the recently reported $B$. burgdorferi strain $\mathrm{B} 31$ chromosome. The other, a 203-bp product amplified from DMC-grown spirochetes, was part of an open reading frame encoding a homologue for MutS, a methyl-directed DNA mismatch repair enzyme (49) which corresponds to gene $B b 098$ from the $B$. burgdorferi strain B31 chromosome (48). The sequence of the 11th product, also specific to DMC-grown organisms, was an exact match for a gene encoding a borrelial lipoprotein (2.9$7 \mathrm{LpB}$ ) which belongs to a family of differentially expressed genes located on homologous $32-$ and $18-\mathrm{kb}$ circular plasmids $(33,50)$. 2.9-7lpB lies immediately downstream of a related gene which encodes another lipoprotein (2.9-7LpA); sequence analysis suggested that $2.9-7 \mathrm{lp} A$ and $2.9-7 \mathrm{lp} B$ are transcriptionally linked (33). The absence of detectable transcripts for either 2.9-7lp $A$ or $2.9-7 l p B$ in prior Northern analyses indicates that these genes are poorly expressed during in vitro cultivation (33).

The amplification of a portion of the $2.9-7 \mathrm{LpB}$ transcript from chamber-cultivated borreliae enabled us to design an experimental strategy whereby we could further investigate the differential expression of the 2.9-7lp $A$ and $2.9-7 l p B$ genes, while, at the same time, advancing the use of chamber implants as a model system for studying Lyme disease spirochetes in a host-adapted state. First, we used RT-PCR to confirm that 2.97lp $A$ and 2.9-7lp $B$ are selectively expressed by DMC-cultivated spirochetes. As shown in Fig. $8 B$, using primers that span the 2.9-7lp $A$ and 2.9-7lp $B$ genes, a specific product was obtained only from DMC-cultivated organisms; this result also 
A
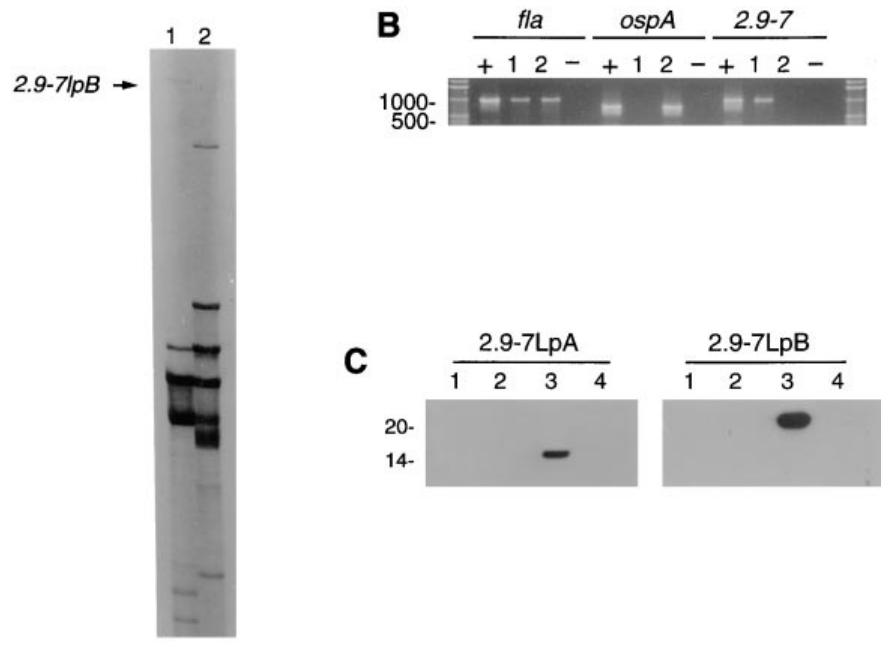

D
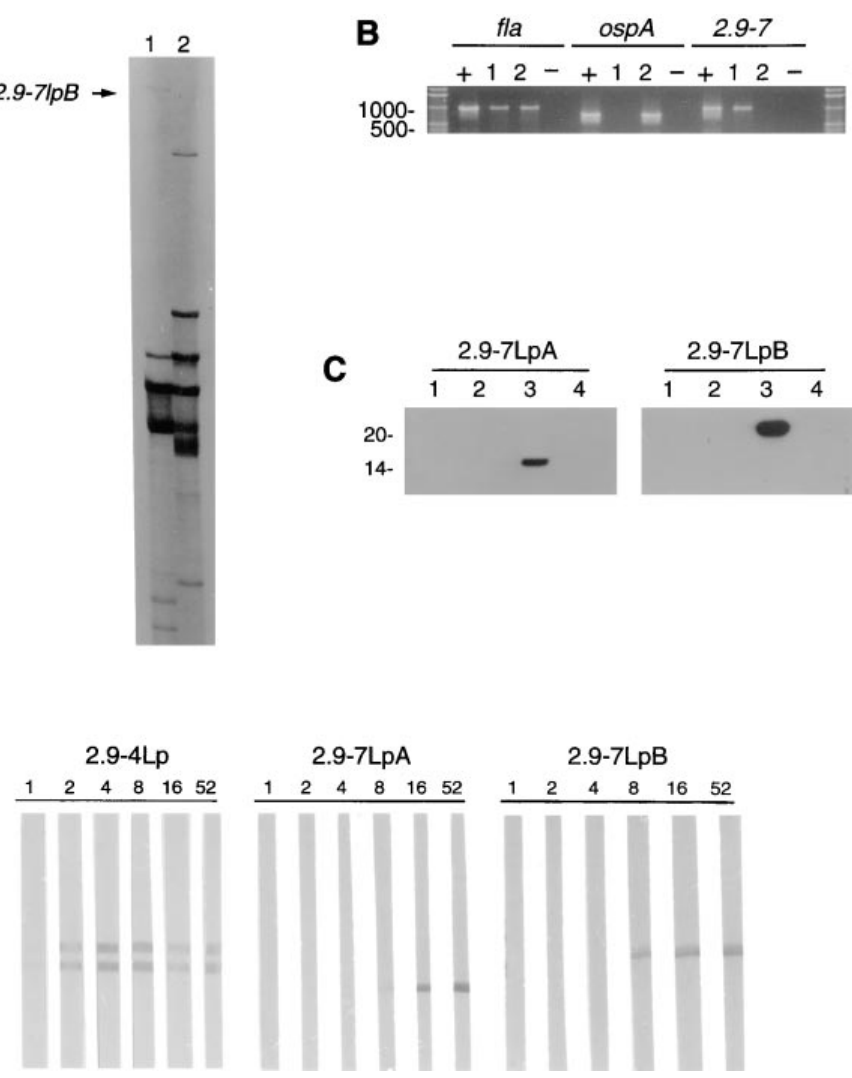

Figure 8. Two circular plasmid-encoded lipoproteins are selectively expressed by spirochetes cultivated in chamber implants and during experimental Lyme disease. $(A)$ Polyacrylamide gel electrophoresis of ddRT-PCR products from chamber-grown (lane 1) and in vitro-cultivated spirochetes (lane 2). The product derived from the 2.9-7lp $B$ transcript is indicated by the arrow. (B) RT-PCR analysis of 2.9-7lpA/B, osp $A$, and fla expression by spirochetes cultivated in DMCs or in vitro. cDNAs generated from $B$. burgdorferi cultivated within DMCs (lane 1) or in vitro (lane 2) were amplified by PCR using primer sets specific for 2.9-7lp $A / B$, osp $A$, and fla. $10 \mu \mathrm{l}$ from each amplification reaction was subjected to agarose gel electrophoresis and stained with ethidium bromide. Amplification reactions with $B$. burgdorferi 297 DNA $(+)$ or water $(-)$ were also included for each primer set to serve as PCR controls. Molecular wt markers are indicated on the left in bp. (C) Immunoblot analysis of whole-cell lysates ( $5 \mu \mathrm{g}$ per lane) of organisms grown in vitro at $23^{\circ} \mathrm{C}$, after temperature-shift at $37^{\circ} \mathrm{C}$, within chamber implants, or in vitro at $34^{\circ} \mathrm{C}$ (lanes $1-4$, respectively) with antisera directed against recombinant $2.9-7 \mathrm{LpA}$ or $2.9-7 \mathrm{LpB}$. (D) Time course for the production of antibodies against 2.9-4Lp, 2.97LpA, and 2.9-7LpB after low-dose needle inoculation of $\mathrm{C} 3 \mathrm{H} /$ $\mathrm{HeJ}$ mice; numbers at the top indicate weeks of infection. The antibody conjugate used for this experiment was capable of detecting both IgG and IgM antibodies. confirmed that the two genes are transcriptionally linked. As expected, transcript for fla was amplified from both in vitroand DMC-cultivated borreliae indicating that this gene is constitutively expressed, while $\operatorname{ssp} A$ transcript was amplified only from the organisms grown in vitro. It should be noted that the lack of a $2.9-7 l p A / B$ or an $\operatorname{ssp} A$ amplicon product with cDNA generated from in vitro- or chamber-cultivated organisms, respectively, ruled out the possibility that the two RNA pools used to generate cDNA were contaminated with genomic DNA. Furthermore, consistent with the above RT-PCR result, immunoblot analysis using specific antisera generated against recombinant forms of $2.9-7 \mathrm{LpA}$ and $2.9-7 \mathrm{LpB}$ revealed that both proteins were expressed by chamber-grown spirochetes but not by organisms cultivated in vitro at 23,34 , or $37^{\circ} \mathrm{C}$ after temperature-shift (Fig. $8 \mathrm{C}$ ). The apparent molecular masses of the antigens detected $(15-$ and $22.5-\mathrm{kD})$ correlated quite closely with the calculated molecular masses of the mature 2.9-7LpA and 2.9-7LpB lipoproteins (15,015 and 22,938 D, respectively) (33). Finally, to verify that $2.9-7 \mathrm{LpA}$ and $2.9-7 \mathrm{LpB}$ are also selectively expressed during infection, the recombinant proteins were immunoblotted against sera from experimentally infected mice. IgM or IgG antibodies reactive with either protein were not detected until at least $8 \mathrm{wk}$ after infection (Fig. $8 \mathrm{D}$ ). In contrast, antibodies directed against another member of this lipoprotein family (2.9-4Lp) which is expressed by spirochetes grown in vitro were detected within 2 wk of infection (Fig. $8 D$ ).

\section{Discussion}

The identification of virulence determinants which are expressed only during infection or within specific host niches has become an area of intensive investigation in the field of bacterial pathogenesis. Particularly important for this work has been the development of reporter constructs for tracking the expression of bacterial genes in vivo or in tissue culture systems $(51,52)$. Analogous studies of Lyme disease pathogenesis are not presently feasible due to the limited ability to genetically manipulate $B$. burgdorferi. Despite this formidable obstacle, in recent years investigators have enjoyed considerable success in implementing strategies for identifying and characterizing differentially expressed borrelial genes which could serve as potential vaccinogens and/or diagnostic reagents (9$13,53)$. While these studies have solidified the notion that $B$. burgdorferi protein composition is dynamic (8), they also have underscored our limited understanding of the extent of these changes and, most importantly, how they relate to the bacterium's parasitic strategies and the course of disease expression.

At the outset, we hypothesized that two types of factors are primarily responsible for inducing host-adaptive changes in Lyme disease spirochetes: $(a)$ the elevated body temperature of the mammalian host and $(b)$ soluble factors in blood and interstitial fluids. This postulate emerged from work with other bacterial pathogens (16) as well as studies demonstrating that some differentially expressed B. burgdorferi proteins are temperature-regulated $(5,17)$, whereas others appear to be modulated by undefined signaling molecules in blood (8). We further speculated that the necessary soluble factors would efficiently traverse both the peritoneum, which is known to be highly permeable to macromolecules $(54,55)$, as well as the comparatively small pores in the dialysis membrane used to contain the spirochetes. With other bacterial pathogens, it has been shown that many of the signals which govern the expression of virulence determinants are small chemicals or com- 
pounds (16). We selected an exclusion limit of 5,000 D based on the presumption that this pore size would allow influx of relevant signaling molecules while excluding the large majority of serum proteins. Analyses using indirect immunofluorescence, gel electrophoresis, immunoblotting, and ddRT-PCR all validated this postulate by demonstrating that spirochetes cultivated within chamber implants underwent profound, yet reversible, alterations in protein composition. While many of the compositional changes involved previously characterized borrelial constituents, altered expression of many uncharacterized borrelial polypeptides also was observed. Additionally, several selectively expressed polypeptides reacted with sera from mice chronically infected with $B$. burgdorferi; this observation strongly suggests that cultivation within DMCs induced phenotypic changes resembling those which occur in spirochetes during infection.

To examine the hypothesis that signaling cues other than temperature contribute to host adaptation by B. burgdorferi, we included in our analyses borreliae cultivated at $37^{\circ} \mathrm{C}$ after temperature shift from $23^{\circ} \mathrm{C}$, a maneuver thought to reproduce the change in temperature coincident with tick feeding (5). Initial support for the existence of nonthermal stimuli came from the markedly different growth kinetics of DMC-cultivated and temperature-shifted spirochetes. Inasmuch as the core temperature of rats is $\sim 37^{\circ} \mathrm{C}(47)$, it is reasonable to presume that the different growth kinetics reflect aspects of the chamber environment unrelated to temperature. The relatively rapid replication which apparently occurred in the early postimplantation period may be analogous to the burst in growth stimulated by the blood meal $(56,57)$. Moreover, the gel and immunoblot analyses demonstrated that DMC-cultivated borreliae not only lacked proteins expressed by temperature-shifted organisms but also expressed unique polypeptides. Interestingly, our analyses also identified temperature-regulated proteins which did not appear to be upregulated in chamber-grown spirochetes, suggesting that, for some genes, nonthermal signals can override the positive stimulus provided by elevated temperature.

An important piece of evidence that chamber-grown spirochetes resembled host-adapted borreliae was the finding that they did not express OspA and Lp6.6, two markers for the in vitro phenotype. To further characterize DMC-cultivated spirochetes, we also probed in vitro- and DMC- grown organisms with antibodies directed against other differentially expressed antigens. Immunoblot analysis revealed that p21, a marker for the in vivo phenotype, was expressed only by spirochetes cultivated in DMCs, while OspE was expressed uniformly in all cultures save those grown at $23^{\circ} \mathrm{C}$. In contrast to $\mathrm{p} 21$, chambergrown spirochetes did not express BbK2.10, an OspF homologue which is also expressed only during infection. Presumably one or more signals (or some combination thereof) necessary for the induction of this protein were missing from the chamber milieu; one possible missing signal may be direct contact between the spirochetes and host tissues. It is also possible that the failure to detect $\mathrm{BbK} 2.10$ reflects potential differences in antigenic structure among spirochetes in various niches or microenvironments as suggested by other research $(22,23)$. Further research will be needed to determine how closely DMCgrown spirochetes reproduce the host-adapted state.

In all B. burgdorferi strains studied to date, the $\operatorname{sp} E, o s p F$, $p 21$, and $b b k 2.10$ genes possess highly similar promoters and flanking sequences $(11,12,58,59)$; thus, ostensibly minor se- quence differences in and around control elements appear to dramatically impact the responses of individual genes in the $o s p E / F$ family to environmental stimuli. Finally, we also identified an abundant 22-kD protein which, like OspA and Lp6.6, was markedly downregulated in chamber-cultivated borreliae. This observation underscores the fact that host adaption involves decreased as well as enhanced gene and protein expression and that elucidation of this phenomenon will undoubtedly require deciphering the signals and regulatory mechanisms responsible for repression as well as induction of borrelial genes.

We reported previously that B. burgdorferi 297 contains three OspF homologues (OspF, BbK2.10, and BbK2.11) (12), two of which (OspF and BbK2.11) are highly cross-reactive (12). Immunoblot analysis of DMC-cultivated organisms with an OspF mAb revealed, surprisingly, that the 297 isolate possibly contains two additional uncharacterized OspF-related polypeptides. Based upon their relative levels of expression in DMC- versus in vitro-cultivated borreliae, it seems likely that these two proteins are selectively expressed during infection. It is has been speculated that the extended lipoprotein gene family which includes both $o s p E$ - and $o s p F$-related genes functions as a system of antigenic variation which enhances $B$. burgdorferi's ability to evade host humoral defenses (59). This conjecture appears to be at variance with our finding that during infection Lyme disease spirochetes may concurrently express as many as four cross-reactive surface-exposed lipoproteins. Alternatively, it is equally plausible, given the variable expression of the four proteins under the different culture conditions studied here, that levels of the individual proteins vary more greatly within the privileged niches encountered by $B$. burgdorferi in vivo than during growth within DMCs.

The genome of B. burgdorferi is unusual among prokaryotes in that it consists of a linear chromosome and numerous linear and circular plasmids $(60,61)$. Plasmids have been implicated as a major genetic repository for the adaptive changes which occur during the bacterium's enzootic cycle by virtue of the facts that $(a)$ loss of plasmids correlates with loss of infectivity (62) and, more recently, (b) all of the genes encoding differentially expressed borrelial polypeptides identified to date have been localized to extrachromosomal elements. Our ddRTPCR results strengthen this generalization. Southern hybridization revealed that the eight ddRT-PCR products which did not match sequences in the databases were plasmid-encoded. Furthermore, a ninth ddRT-PCR product was derived from a selectively expressed lipoprotein gene (2.9-7lp $B$ ) which we reported previously was located on a circular plasmid (33). The RT-PCR experiments with primers specific for the 2.9-7lp $A / B$ operon also were noteworthy because they demonstrated the potential utility of DMC-grown organisms for transcriptional analysis of differentially expressed $B$. burgdorferi genes; previously such genes could be transcriptionally analyzed only with B. burgdorferi-infected tissues.

Lyme disease investigators have long been perplexed by the observation that the antibodies generated during borrelial infection can kill spirochetes in vitro but are unable to eradicate the infecting spirochetes (63). Similarly, it has been shown more recently that passive transfer of immune serum can prevent against infection by in vitro-cultivated organisms but cannot protect against infection by tick inoculation or with hostadapted organisms $(23,35)$. By providing sizable numbers of host-adapted spirochetes whose surfaces can be directly examined, the chamber implant model described here provides a 
unique capability for addressing these enigmas which are thought to be central to the issue of spirochetal persistence during Lyme disease. This model also has the potential to facilitate the identification of novel targets for borreliacidal antibodies. This is an important consideration given that a major weakness of the OspA vaccine currently undergoing clinical evaluation is its apparent lack of efficacy against established infection $(21,64)$ coupled with the perceived difficulty in eradicating spirochetes with conventional antimicrobial therapy (65-67).

\section{Acknowledgments}

We are indebted to Minyue Li and Lauren Thacker for superb technical assistance and to Kayla Hagman and Taissia Popova for providing important reagents. We also wish to thank Dmitriy Shevchenko for helpful discussions, Leslie Arndt for producing mAbs, and George Schoeler and Stephen Wikel for allowing us to cite their unpublished observations regarding the expression of Lp6.6.

This work was partially supported by grant AI-29735 from the National Institute of Allergy and Infectious Diseases (National Institutes of Health).

\section{References}

1. Baranton, G., D. Postic, I. Saint Girons, P. Boerlin, J.C. Piffaretti, M. Assous, and P.A. Grimont. 1992. Delineation of Borrelia burgdorferi sensu stricto, Borrelia garinii sp. nov. and group VS461 associated with Lyme borreliosis. Int. J. Syst. Bacteriol. 42:378-383.

2. Nocton, J.J., and A.C. Steere. 1995. Lyme disease. Adv. Intern. Med. 40: 69-117.

3. Lane, R.S., J. Piesman, and W. Burgdorfer. 1991. Lyme borreliosis: relation of its causative agent to its vectors and hosts in North America and Europe. Ann. Rev. Entomol. 36:587-609.

4. Smith, R.P., Jr., P.W. Rand, E.H. Lacombe, S.R. Telford, S.M. Rich, J. Piesman, and A. Spielman. 1993. Norway rats as reservoir hosts for Lyme disease spirochetes on Monhegan Island, Maine. J. Infect. Dis. 168:687-691.

5. Schwan, T.G., J. Piesman, W.T. Golde, M.C. Dolan, and P.A. Rosa. 1995. Induction of an outer surface protein on Borrelia burgdorferi during tick feeding. Proc. Natl. Acad. Sci. USA. 92:2909-2913.

6. Montgomery, R.K., S.E. Malawista, K.J.M. Feen, and L.K. Bockenstedt. 1996. Direct demonstration of antigenic substitution of Borrelia burgdorferi ex vivo: exploration of the paradox of the early immune response to outer surface proteins A and C in Lyme disease. J. Exp. Med. 183:261-269.

7. de Silva, A.M., S.R. Telford, L.R. Brunet, S.W. Barthold, and E. Fikrig. 1996. Borrelia burgdorferi OspA is an arthropod-specific transmission-blocking Lyme disease vaccine. J. Exp. Med. 183:271-275.

8. de Silva, A.M., and E. Fikrig. 1997. Arthropod- and host-specific gene expression by Borrelia burgdorferi. J. Clin. Invest. 99:377-379.

9. Champion, C.I., D.R. Blanco, J.T. Skare, D.A. Haake, M. Giladi, D. Foley, J.N. Miller, and M.A. Lovett. 1994. A 9.0 kilobase-pair circular plasmid of Borrelia burgdorferi encodes an exported protein: evidence for expression only during infection. Infect. Immun. 62:2653-2661.

10. Fikrig, E., S.W. Barthold, W. Sun, W. Feng, S.R. Telford, and R.A. Flavell. 1997. Borrelia burgdorferi $\mathrm{p} 35$ and $\mathrm{p} 37$ proteins, expressed in vivo, elicit protective immunity. Immunity. 6:531-539.

11. Suk, K., S. Das, W. Sun, B. Jwang, S.W. Barthold, R.A. Flavell, and E. Fikrig. 1995. Borrelia burgdorferi genes selectively expressed in the infected host. Proc. Natl. Acad. Sci. USA. 92:4269-4273.

12. Akins, D.R., S.F. Porcella, T.G. Popova, D. Shevchenko, S.I. Baker, M. Li, M.V. Norgard, and J.D. Radolf. 1995. Evidence for in vivo but not in vitro expression of a Borrelia burgdorferi outer surface protein $\mathrm{F}(\mathrm{OspF})$ homolog. Mol. Microbiol. 18:507-520.

13. Wallich, R., C. Brenner, M.D. Kramer, and M.M. Simon. 1995. Molecular cloning and immunological characterization of a novel linear-plasmidencoded gene, $p G$, of Borrelia burgdorferi expressed only in vivo. Infect. Immun. 63:3327-3335.

14. Lahdenne, P., S.F. Porcella, K.E. Hagman, D.R. Akins, T.G. Popova, D.L. Cox, J.D. Radolf, and M.V. Norgard. 1997. Molecular characterization of a 6.6-kilodalton Borrelia burgdorferi outer membrane-associated lipoprotein (lp6.6) which appears to be downregulated during mammalian infection. Infect. Immun. 65:412-421.

15. Mekalanos, J.J. 1992. Environmental signals controlling expression of virulence determinants in bacteria. J. Bacteriol. 174:1-7.
16. Guiney, D.G. 1997. Regulation of bacterial virulence gene expression by the host environment. J. Clin. Invest. 99:565-569.

17. Stevenson, B., T.G. Schwan, and P.A. Rosa. 1995. Temperature-related differential expression of antigens in the Lyme disease spirochete, Borrelia burgdorferi. Infect. Immun. 63:4535-4539.

18. Das, S., S.W. Barthold, S.S. Giles, R.R. Montgomery, S.R. Telford III, and E. Fikrig. 1997. Temporal pattern of Borrelia burgdorferi p21 expression in ticks and mammalian host. J. Clin. Invest. 99:987-995.

19. Dressler, F., J.A. Whalen, B.N. Reinhardt, and A.C. Steere. 1993. Western blotting in the serodiagnosis of Lyme disease. J. Infect. Dis. 167:392-400.

20. Craft, J.E., D.K. Fischer, G.T. Shimamoto, and A.C. Steere. 1986. Antigens of Borrelia burgdorferi recognized during Lyme disease. Appearance of a new immunoglobulin $\mathrm{M}$ response and expansion of the immunoglobulin $\mathrm{G}$ response late in the illness. J. Clin. Invest. 78:934-939.

21. Barthold, S.W., E. Fikrig, L.K. Bockenstedt, and D.H. Persing. 1995. Circumvention of outer surface protein A immunity by host-adapted Borrelia burgdorferi. Infect. Immun. 63:2255-2261.

22. Barthold, S.W., S.L. Feng, L.K. Bockenstedt, E. Fikrig, and K. Feen 1997. Protective and arthritis-resolving activity in sera of mice infected with Borrelia burgdorferi. Clin. Infect. Dis. 25:S9-S17.

23. de Silva, A.M., E. Fikrig, E. Hodzie, F.S. Kantor, S.R. Telford III, and S.W. Barthold. 1998. Immune evasion by tickborne and host-adapted Borrelia burgdorferi. J. Infect. Dis. 177:395-400.

24. Arbuthnott, J.P., E.R. Arbuthnott, A.D. Arbuthnott, W.J. Pike, and A. Cockayne. 1992. Investigation of microbial growth in vivo: evaluation of a novel in vivo chamber implant system. FEMS Microbiol. Lett. 79:75-79.

25. Kelly, N.M., A. Bell, and R.E. Hancock. 1989. Surface characteristics of Pseudomonas aeruginosa grown in a chamber implant model in mice and rats. Infect. Immun. 57:344-350.

26. Jonsson, M., T. Elmros, and S. Bergstrom. 1995. Subcutaneous implanted chambers in different mouse strains as an animal model to study genetic stability during infection with Lyme disease Borrelia. Microb. Pathog. 18: $109-114$.

27. Hurtenbach, U., C. Museteanu, J. Gasser, U.E. Schaible, and M.M. Simon. 1995. Studies on early events of Borrelia burgdorferi-induced cytokine production in immunodeficient SCID mice by using a tissue chamber model for acute inflammation. Int. J. Exp. Pathol. 76:111-123.

28. Steere, A.C., R.L. Grodzicki, A.N. Kornblatt, J.E. Craft, A.G. Barbour, W. Burgdorfer, G.P. Schmid, E. Johnson, and S.E. Malawista. 1983. The spirochetal etiology of Lyme disease. N. Engl. J. Med. 308:733-740.

29. Barbour, A.G. 1984. Isolation and cultivation of Lyme disease spirochetes. Yale J. Biol. Med. 57:521-525.

30. Smith, D.B., and K.S. Johnson. 1988. Single-step purification of polypeptides expressed in Escherichia coli as fusions with glutathione $S$-transferase. Gene. 67:31-40.

31. Sinsky, R.J., and J. Piesman. 1989. Ear punch biopsy method for detection and isolation of Borrelia burgdorferi from rodents. J. Clin. Microbiol. 27: 1723-1727.

32. Lam, T.T., T.P.K. Nguyen, R.R. Montgomery, F.S. Kantor, E. Fikrig, and R.A. Flavell. 1994. Outer surface proteins E and F of Borrelia burgdorferi, the agent of Lyme disease. Infect. Immun. 62:290-298.

33. Porcella, S.F., T.G. Popova, D.R. Akins, M. Li, J.D. Radolf, and M.V. Norgard. 1996. Borrelia burgdorferi supercoiled plasmids encode multiple tandem open reading frames and a lipoprotein gene family. J. Bacteriol. 178:32933307.

34. Weigel, L.M., M.E. Brandt, and M.V. Norgard. 1992. Analysis of the $\mathrm{N}$-terminal region of the 47-kilodalton integral membrane lipoprotein of Treponema pallidum. Infect. Immun. 60:1568-1576.

35. Cox, D.L., D.R. Akins, K.W. Bourell, P. Lahdenne, M.V. Norgard, and J.D. Radolf. 1996. Limited surface exposure of Borrelia burgdorferi outer surface lipoproteins. Proc. Natl. Acad. Sci. USA. 93:7973-7978.

36. Katona, L.I., G. Beck, and G.S. Habicht. 1992. Purification and immunological characterization of a major low-molecular-weight lipoprotein from Borrelia burgdorferi. Infect. Immun. 60:4995-5003.

37. Swancutt, M.A., D.A. Twehous, and M.V. Norgard. 1986. Monoclonal antibody selection and analysis of a recombinant DNA-derived surface immunogen of Treponema pallidum expressed in Escherichia coli. Infect. Immun. 52: $110-119$.

38. Morrissey, J.H. 1981. Silver stain for proteins in polyacrylamide gels: a modified procedure with enhanced uniform sensitivity. Anal. Biochem. 117: 307-310.

39. Bradford, M.M. 1976. A rapid and sensitive method for the quantitation of microgram quantities of protein utilizing the principle of protein-dye binding. Anal. Biochem. 72:248-254.

40. O'Farrell, P.Z., H.M. Goodman, and P.H. O'Farrell. 1977. High-resolution two-dimensional electrophoresis of basic as well as acidic proteins. Cell. 12 1133-1142.

41. Devereux, J., P. Haeberli, and O. Smithies. 1984. A comprehensive set of sequence analysis programs for the VAX. Nucleic Acids Res. 12:387-395.

42. Abouhamad, W.N., and M.D. Manson. 1994. The dipeptide permease of Escherichia coli closely resembles other bacterial transport systems and shows growth-phase-dependent expression. Mol. Microbiol. 14:1077-1092. 
43. Dersch, P., K. Schmidt, and E. Bremer. 1993. Synthesis of the Escherichia coli K-12 nucleoid-associated DNA-binding protein H-NS is subjected to growth-phase control and autoregulation. Mol. Microbiol. 8:875-889.

44. Givskov, M., and S. Molin. 1992. Expression of extracellular phospholipase from Serratia liquefaciens is growth-phase-dependent, catabolite-repressed, and regulated by anaerobiosis. Mol. Microbiol. 6:1363-1374.

45. Mikulskis, A.V., I. Delor, V.H. Thi, and G.R. Cornelis. 1994. Regulation of the Yersinia enterocolitica enterotoxin Yst gene. Influence of growth phase, temperature, osmolarity, $\mathrm{pH}$, and bacterial host factors. Mol. Microbiol. 14: 905-915.

46. Indest, K.J., R. Ramamoorthy, M. Sole, R.D. Gilmore, B.J.B. Johnson, and M.T. Philipp. 1997. Cell-density-dependent expression of Borrelia burgdorferi lipoproteins in vitro. Infect. Immun. 65:1165-1171.

47. Harkness, J.E., and J.E. Wagner. 1995. The Biology and Medicine of Rabbits and Rodents. Williams and Wilkins, Baltimore, MD. 372 pp.

48. Fraser, C.M., S. Casjens, W.M. Huang, G.G. Sutton, R. Clayton, R. Lathigra, O. White, K.A. Ketchum, R. Dodson, E.K. Hickey, et al. 1997. Genomic sequence of a Lyme disease spirochete, Borrelia burgdorferi. Nature. 390:580-586.

49. Modrich, P. 1991. Mechanisms and biological effects of mismatch repair. Ann. Rev. Gen. 25:229-253.

50. Stevenson, B., S. Casjens, R. van Vugt, S.F. Porcella, K. Tilly, J.L. Bono, and P. Rosa. 1997. Characterization of cp18, a naturally truncated member of the cp32 family of Borrelia burgdorferi plasmids. J. Bacteriol. 179:4285-4291.

51. Valdivia, R.H., and S. Falkow. 1997. Probing bacterial gene expression within host cells. Trends Microbiol. 25:360-363.

52. Slauch, J.M., M.J. Mahan, and J.J. Mekalanos. 1994. In vivo expression technology for selection of bacterial genes specifically induced in host tissues. Meth. Enzymol. 235:481-492.

53. Foley, D.M., Y.-P. Wang, X.-Y. Wu, D.R. Blanco, M.A. Lovett, and J.N. Miller. 1997. Acquired resistance to Borrelia burgdorferi in the rabbit. Comparison between outer surface protein A vaccine- and infection-derived immunity. J. Clin. Invest. 99:2030-2035.

54. Dulaney, J.T., and F.E. Hatch, Jr. 1984. Peritoneal dialysis and loss of proteins: a review. Kidney Int. 26:253-262.

55. Krediet, R.T., G.C. Koomen, M.G. Koopman, F.J. Hoek, D.G. Struijk, E.W. Boeschoten, and L. Arisz. 1989. The peritoneal transport of serum pro- teins and neutral dextran in CAPD patients. Kidney Int. 35:1064-1072.

56. Burkot, T.R., J. Piesman, and R.A. Wirtz. 1994. Quantitation of the Borrelia burgdorferi outer surface protein A in Ixodes scapularis: fluctuation during the tick life cycle, doubling times, and loss while feeding. J. Infect. Dis. 170:883-889.

57. de Silva, A.M., and E. Fikrig. 1995. Growth and migration of Borrelia burgdorferi in Ixodes ticks during blood feeding. Am. J. Trop. Med. Hyg. 53: 397-404.

58. Casjens, S., R. van Vugt, K. Tilly, P.A. Rosa, and B. Stevenson. 1997. Homology throughout the multiple 32-kilobase circular plasmids present in Lyme disease spirochetes. J. Bacteriol. 179:217-227.

59. Marconi, R.T., S.Y. Sung, C.A. Hughes, and J.A. Carlyon. 1996. Molecular and evolutionary analyses of a variable series of genes in Borrelia burgdor feri that are related to $\operatorname{sp} E$ and $\operatorname{sp} F$, constitute a gene family, and share a common upstream homology box. J. Bacteriol. 178:5615-5626.

60. Saint Girons, I., I.G. Old, and B.E. Davidson. 1994. Molecular biology of the Borrelia, bacteria with linear replicons. Microbiology. 140:1803-1816.

61. Barbour, A.G. 1989. The molecular biology of Borrelia. Rev. Infect. Dis. 11(Suppl. 6):S1470-S1474

62. Schwan, T.G., W. Burgdorfer, and C.F. Garon. 1988. Changes in infectivity and plasmid profile of the Lyme disease spirochete, Borrelia burgdorferi, as a result of in vitro cultivation. Infect. Immun. 56:1831-1836.

63. Callister, S.M., R.F. Schell, and S.D. Lovrich. 1991. Lyme disease assay which detects killed Borrelia burgdorferi. J. Clin. Microbiol. 29:1773-1776.

64. Fikrig, E., S.W. Barthold, and R.A. Flavell. 1993. OspA vaccination of mice with established Borrelia burgdorferi infection alters disease but not infection. Infect. Immun. 61:2553-2557.

65. Bayer, M.E., L. Zhang, and M.H. Bayer. 1996. Borrelia burgdorferi DNA in the urine of treated patients with chronic Lyme disease symptoms. A PCR study of 97 cases. Infection. 24:347-353.

66. Asch, E.S., D.I. Bujak, M. Weiss, M.G. Peterson, and A. Weinstein 1994. Lyme disease: an infectious and postinfectious syndrome. J. Rheum. 21: 454-461.

67. Straubinger, R.K., B.A. Summers, Y.-F. Chang, and M.J.G. Appel. 1997. Persistence of Borrelia burgdorferi in experimentally infected dogs after antibiotic treatment. J. Clin. Microbiol. 35:111-116. 